\title{
Generation Rate of Carbon Monoxide from Burning Charcoal
}

\author{
Jun OJIMA ${ }^{1}$ \\ ${ }^{1}$ National Institute of Occupational Safety and Health, 6-21-1 Nagao, Tama-ku, Kawasaki 214-8585, Japan \\ Received March 15, 2010 and accepted November 2, 2010 \\ Published online in J-STAGE March 1, 2011
}

\begin{abstract}
Charcoal, often used as cooking fuel at some restaurants, generates a significant amount of carbon monoxide (CO) during its combustion. Every year in Japan, a number of cooks and waiters/waitresses are poisoned by $\mathrm{CO}$ emanating from burning charcoal. Although certain ventilation is necessary to prevent the accumulation of $\mathrm{CO}$, it is difficult to estimate the proper ventilation requirement for $\mathrm{CO}$ because the generation rate of $\mathrm{CO}$ from burning charcoal has not been established. In this study, several charcoals were evaluated in terms of CO generation rate. Sample charcoals were burned in a cooking stove to generate exhaust gas. For each sample, four independent variables - the mass of the sample, the flow rate of the exhaust gas, $\mathrm{CO}$ concentration in the exhaust gas and the combustion time of the sample were measured, and the $\mathrm{CO}$ generation rate was calculated. The generation rate of $\mathrm{CO}$ from the charcoal was shown to be $137-185 \mathrm{ml} / \mathrm{min} / \mathrm{kW}$. Theoretical ventilation requirements for charcoals to prevent $\mathrm{CO}$ poisoning are estimated to be $41.2-55.6 \mathrm{~m}^{3} / \mathrm{h} / \mathrm{kW}$.
\end{abstract}

Key words: Carbon monoxide, Charcoal, Gas generation rate, Ventilation

\section{Introduction}

Carbon monoxide $(\mathrm{CO})$ is a potent, lethal gas that can overcome exposed persons without warning. In recent years, $\mathrm{CO}$ poisoning in Japanese workplaces has been increasing and $\mathrm{CO}$ poisoning now accounts for about $50 \%$ of all industrial hazards due to chemical substances. Incomplete combustion in a portable gasoline-powered engine ${ }^{1)}$ used at a construction site is the most common cause of industrial $\mathrm{CO}$ poisoning in Japan, and improper using of cooking utensils such as a range or an oven in a restaurant is the second most common cause of $\mathrm{CO}$ poisoning. While natural gas and propane gas are the most prevalent cooking fuels in Japan, charcoal cannot be ignored because of the incident of CO poisoning. Since burning charcoal radiates intense infrared radiation and enhances the flavor of broiled meat, it is commonly used as a cooking fuel at some Japanese restaurants serving "Kabayaki" (barbecued eel), "Yakitori" (grilled chicken on a stick) or "Yakiniku" (roast beef). Charcoal also generates a

E-mail: ojima@h.jniosh.go.jp significant amount of $\mathrm{CO}$ during its combustion which can easily cause accumulation of $\mathrm{CO}$ in a room. Every year in Japan, a number of cooks, waiters and waitresses are poisoned in the kitchen or semi-enclosed spaces by $\mathrm{CO}$ generated by burning charcoal. Although some mechanical ventilation is necessary to prevent the accumulation of $\mathrm{CO}$ in semi-enclosed spaces, it is difficult to estimate the proper ventilation requirement for $\mathrm{CO}$ control because the generation rate of $\mathrm{CO}$ from burning charcoal has not been established. Insofar as charcoal is concerned, no empirical evaluation of $\mathrm{CO}$ generation has been published to date; therefore, the presented study aimed to evaluate the generation rate of $\mathrm{CO}$ from burning charcoal under controlled laboratory conditions and estimate the ventilation requirements for the prevention of $\mathrm{CO}$ poisoning.

\section{Experimental Methods}

All sample charcoals used in this study were domestic oak charcoals (namely "Bincho-Tan") which are commercially available as solid fuel for cooking. "BinchoTan" is the most popular charcoal in the Japanese 
Table 1. Profile of sample charcoals

\begin{tabular}{crrl}
\hline Sample & \multicolumn{1}{c}{ Trade name } & Production region & \multicolumn{1}{c}{ Raw timber } \\
\hline A & Kisyu Bincho-Tan & Wakayama Pref. & Quercus phillyraeoides* \\
B & Tosa Bincho-Tan & Kochi Pref. & Quercus phillyraeoides \\
C & Hyuga Bincho-Tan & Miyazaki Pref. & Quercus glauca** \\
D & Bungo Bincho-Tan & Oita Pref. & Quercus glauca \\
E & Iyo Bincho-Tan & Ehime Pref. & Quercus phillyraeoides \\
\hline
\end{tabular}

*, **; a kind of live oak.

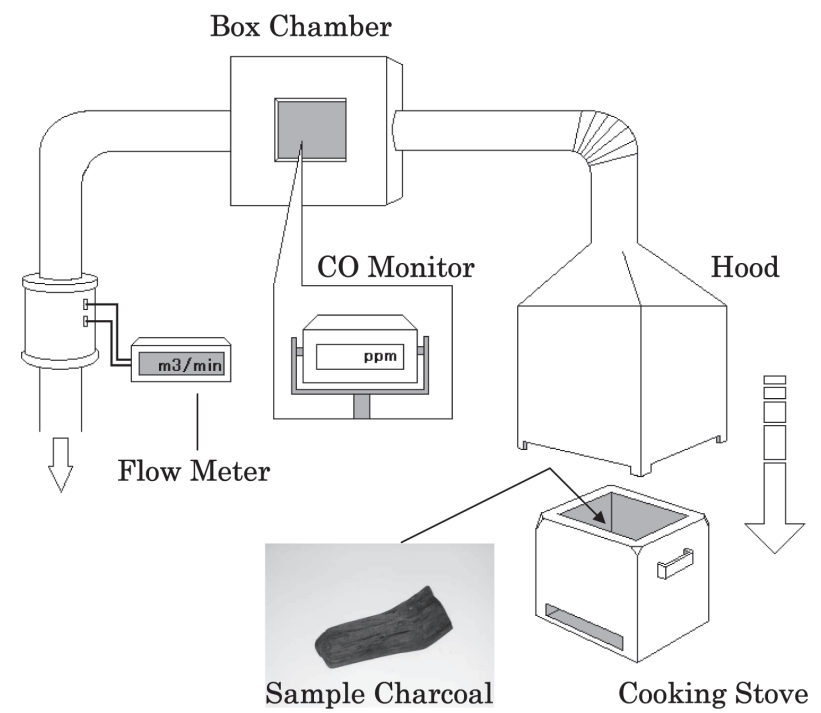

Fig. 1. Schematic diagram of the equipment used in the charcoal burning experiments.

kitchen because it keeps burning for a long time and is suitable for grilling. Table 1 shows brief profiles of the sample charcoals.

Figure 1 shows the experimental set-up for this study. A $50-100 \mathrm{~g}$ sample charcoal piece was weighed on an electric balance and was then burned in a Japanese traditional portable clay cooking stove; "Shichirin" $(0.3 \mathrm{~m} \times 0.3 \mathrm{~m} \times 0.23 \mathrm{~m})$. During the charcoal burning, the cooking stove was enclosed by a metal cover hood which sucked up all the exhaust gas from the burning charcoal. A flexible duct of $\phi 80 \mathrm{~mm}$ was connected to the top of the cover hood, and the exhaust gas passed through a box chamber $(0.3 \mathrm{~m} \times 0.3 \mathrm{~m} \times 0.3 \mathrm{~m})$ which contained a real-time $\mathrm{CO}$ monitor (Gas Detector XC-2200 Model; New Cosmos Electric Co., Ltd., Japan). The box chamber had an observation window through which the $\mathrm{CO}$ monitor could easily be read. The path length of the exhaust gas from the hood take-off to the box chamber was about $1.5 \mathrm{~m}$, which was thought to be sufficient enough to make the exhaust gas homogeneous ${ }^{2)}$. The flow rate of the exhaust gas was measured continuously by means of an air flow meter (New Aero-Eye AE150D Q-system; Wetmaster Co., Ltd., Japan) which was located $2 \mathrm{~m}$ downstream of the box chamber. Since the flow rate was regulated at approximately $2 \mathrm{~m}^{3} / \mathrm{min}$, the burning charcoal was sufficiently supplied with air induced through the clearance between the hood and floor. The combustion time of the sample charcoal was defined as the period from the ignition to the extinction in this experiment.

With the substitution of the four measurements - the mass of the sample, the flow rate of the exhaust gas, $\mathrm{CO}$ concentration in the exhaust gas and the combustion time of the sample - into the following equation, the generation rate of $\mathrm{CO}$ from each sample charcoal was obtained.

$$
\mathrm{G}=\left(\mathrm{V}_{\mathrm{ex}} \cdot \mathrm{t} \cdot \mathrm{C}_{\mathrm{CO}} \cdot 10^{-6}\right) / \mathrm{t}
$$

where $\mathrm{G}$ : generation rate of $\mathrm{CO}\left(\mathrm{m}^{3} / \mathrm{min}\right)$

$\mathrm{V}_{\mathrm{ex}}$ : average flow rate of the exhaust gas $\left(\mathrm{m}^{3} / \mathrm{min}\right)$

$\mathrm{C}_{\mathrm{CO}}$ : average $\mathrm{CO}$ concentration in the exhaust gas (ppm)

$\mathrm{t}$ : combustion time of the sample (min)

In order to standardize each generation rate, the author converted them to per power (heat release rate) values using equation (2). Through this conversion, the effect of the fluctuations in the combustion conditions of each sample can be excluded. The calorific value of the oak charcoal used in this equation was 7.669 (kcal/g) based on data from a 2004 Fukuoka Forest Research \& Extension Center study ${ }^{3}$.

$$
\begin{aligned}
\mathrm{G}\left(\mathrm{m}^{3} / \mathrm{min} / \mathrm{kW}\right)= & \mathrm{G}\left(\mathrm{m}^{3} / \mathrm{min}\right) \cdot 860(\mathrm{kcal} / \mathrm{h} / \mathrm{kW}) \cdot \\
& \mathrm{t} / 7.669(\mathrm{kcal} / \mathrm{g}) / \mathrm{w} / 60
\end{aligned}
$$

where $\mathrm{w}$ : weight of the sample $(\mathrm{g})$

All experiments were conducted in a well-ventilated laboratory which was free from ambient CO contamination.

\section{Results and Discussion}

The generation rates of $\mathrm{CO}$ from the burning charcoals are shown in Table 2. All data are given as the arithmetic mean of ten repeated tests. The generation rate of CO was shown to be $137-185 \mathrm{ml} / \mathrm{min} / \mathrm{kW}$. In spite of an ample air supply, which was much larger than the theoretically required air volume, a certain amount of $\mathrm{CO}$ was generated from the charcoal suggesting there are differences in the $\mathrm{CO}$ formation mecha- 
Table 2. CO generation rate and ventilation requirement for each charcoal sample

\begin{tabular}{ccc}
\hline Sample & CO generation rate $(\mathrm{ml} / \mathrm{min} / \mathrm{kW})^{*}$ & Ventilation requirement $\left(\mathrm{m}^{3} / \mathrm{h} / \mathrm{kW}\right)^{*}$ \\
\hline A & $185 \pm 31$ & $55.6 \pm 9.3$ \\
B & $141 \pm 18$ & $42.5 \pm 5.4$ \\
C & $145 \pm 14$ & $43.5 \pm 4.2$ \\
D & $142 \pm 23$ & $42.6 \pm 6.9$ \\
E & $137 \pm 16$ & $41.2 \pm 4.8$ \\
\hline
\end{tabular}

*Values are mean $\pm \mathrm{SD}(\mathrm{n}=10)$.

nisms between charcoal and other fuels ${ }^{4-8)}$.

The ventilation rate needed to maintain a constant concentration at a uniform generation rate was derived using a simple material balance formula ${ }^{9)}$. The accumulation rate of a contaminant in a room can be described as follows.

Accumulation rate $=$ Generation rate - Removal rate that is,

$$
\mathrm{V}(\mathrm{dC} / \mathrm{dt})=\mathrm{G}-\mathrm{Q} \mathrm{C}
$$

where $\mathrm{V}$ : volume of room

$\mathrm{G}$ : generation rate

Q : ventilation rate (effective exhaust flow rate)

$\mathrm{C}$ : concentration of contaminant

$\mathrm{t}$ : time

at a steady state, $\mathrm{dC}=0$ then

$\mathrm{Q}=\mathrm{G} / \mathrm{C}$

By substituting numerical values for $\mathrm{G}$ and $\mathrm{C}$ in equation (4), the ventilation rate can be readily calculated. It should be noted that the ventilation rate is determined without regard to the room volume. According to equation (4), the ventilation requirement in the burning of charcoal to prevent $\mathrm{CO}$ poisoning can be obtained when the Threshold Limit Value (TLV) for CO is substituted for C. Table 2 shows the theoretical ventilation requirement for each sample. In this study, the current ceiling value for $\mathrm{CO}$ set by the National Institute of Occupational Safety and Health (NIOSH: 200 ppm) was adopted as the TLV. The result of the calculation indicates that the $\mathrm{CO}$ concentration in a room will be maintained below the TLV providing the ventilation rate in the room is $41.2-55.6 \mathrm{~m}^{3} / \mathrm{h} / \mathrm{kW}$.

Considering the air-tightness of modern Japanese houses or buildings ${ }^{10)}$, the natural ventilation in some restaurants can't be expected to adequately remove generated CO. Therefore, workers in such restaurants should be informed that opened windows or doors will not provide sufficient ventilation, and some additional mechanical ventilation should be installed.

Without some practical and effective precautionary measures, the number of $\mathrm{CO}$ poisoning cases in the Japanese food-service industry will probably increase in the near future because the annual consumption of charcoal in Japan has recently been increasing. Although the kinds of charcoal and the methodology used in this study were somewhat limited, the result of this study is expected to be helpful for the design of ventilation systems at some restaurants.

\section{References}

1) Earnest GS, Mickelsen RL, McCammon JB, O'Brien DM (1997) Carbon monoxide poisonings from small, gasoline-powered, internal combustion engines: just what is a "well-ventilated area?" Am Ind Hyg Assoc J 58, 787-91.

2) Hampl V, Niemela R, Shulman S, Bartley D (1986) Use of tracer gas technique for industrial exhaust hood efficiency evaluation -Where to sample? Am Ind Hyg Assoc J 47, 281-7.

3) Annual Report of Fukuoka Forest Research \& Extension Center (2004) Development of the alternative to Bincyo-Tan by use of bamboo. http://ffrec.pref. fukuoka.lg.jp/publica/pdf/annual01/h16.pdf. Accessed July 19, 2010 (in Japanese).

4) Pitts WM (1997) Algorithm for estimating carbon monoxide formation in enclosure fires. Fire Safety Science - Proceeding of the fifth international symposium, 535-46.

5) Pitts WM (1996) Carbon monoxide formation algorithm. Fire Research and Safety 13th joint panel meeting 2, 51-9.

6) Pitts WM, Johnsson EL, Bryner NP (1994) Carbon monoxide formation in fires by high-temperature anaerobic wood pyrolysis. Combustion institute symposium (international) on combustion 25th proceeding, 1455-62.

7) Pitts WM (1990) Carbon monoxide production and prediction. Fire Research and Safety 11th joint panel meeting, 33-9.

8) Wu PK, Orloff L, Tewarson A (1997) Assessment of material flammability with the FSG propagation model and laboratory test methods. Fire Research and Safety 13th joint panel meeting 1, 153-64.

9) General Industrial Ventilation. In: Industrial Ventilation 22nd Ed., American Conference of Governmental Industrial Hygienists (Eds.), 2-1, 2-16, ACGIH, Cincinnati.

10) Ikeda K (1998) Actual state of ventilation. In: Cause and countermeasure technologies of indoor air pollutants, Ikeda K, 213-222, Nikkan kogyo shimbun, Tokyo (in Japanese). 